\title{
Artificial Neural Networks Model for Springback Prediction in the Bending Operations
}

\author{
Florica Mioara SERBAN, Sorin GROZAV, Vasile CECLAN, Antoniu TURCU
}

\begin{abstract}
The aim of this paper is to develop an Artificial Neural Network (ANN) model for springback prediction in the free cylindrical bending of metallic sheets. The proposed ANN model was developed and tested using the Matlab software. The input parameters of the proposed ANN model were the sheet thickness, punch radius, and coefficient of friction. The resulting data is represented by the springback coefficient. Preparation, assessing and confirmation of the model were achieved using 126 data series obtained by Finite element analysis (FEA). ANN was trained by Levenberg - Marquardt back - propagation algorithm. The performance of the ANN model was evaluated using statistic measurements. The predictions of the ANN model, regarding FEA, had quite low root mean squared error (RMSE) values and the model performed well with the coefficient of determination values. This shows that the developed ANN model leads to the idea of being used as an instrument for springback prediction.
\end{abstract}

Keywords: artificial neural networks; finite element simulation; springback prediction

\section{INTRODUCTION}

Modelling is a powerful tool used in almost all applicative and engineering fields, instead of doing laboratory tests to reduce time and save money. It is widely established that for modelling large-scale complex processes, soft computing methodology can be effectively used, since this technique is basically designed to exploit the tolerance for imprecision, uncertainty and partial truth. The evolution of soft computing techniques helps in understanding various aspects of nonlinear systems and thereby making it possible to model them besides predicting their future response [1]. The core of soft computing is composed of methodologies such as artificial neural networks (ANNs), fuzzy inference system (FIS), and genetic algorithm (GA), having a similar ability of the human brain to reason and learn in an environment of imprecision and uncertainty which characterises the complex nonlinear system $[2,3]$.

During the last 20 years, researchers explored the potential of artificial neural networks (ANNs) as an analytical alternative to conventional methods [4-6], which are often limited by strict assumptions of linearity, normality, homogeneity, and variable independence [7], to solve complex problems in various disciplines which include computing, science, engineering, medicine, environmental, agriculture, mining, technology, climate, business, arts, and nanotechnology [8]. Thus, ANN was applied by researchers to modelling, forecasting, pattern recognition, estimation and more.

$\mathrm{Xu}$ [9] developed an ANN model capable to predict the ultimate bearing capacity in case of tubular T-joint under fire. In [7] the authors developed a back-propagation neural network and an adaptive neuro-fuzzy inference system model which have the ability to predict the moment capacity of ferro-cement members. Also, ANN models were used in [10] to predict the mechanical properties of ST14 steel trying to save product quality control costs and time. Zgoul [11] developed an ANN model for characterizing the rate dependent behaviour of adhesive materials. The developed model was used to predict true strain, true stress, strain rate, and modulus of elasticity under different conditions. Duan et al. [12] used ANN for predicting the compressive strength of recycled aggregate concrete prepared with various types and sources of recycled aggregates. ANN and adaptive neuro-fuzzy inference system methods were employed in [1] in order to make prediction on the mechanical properties of glass fibre reinforced polymers. The adaptive neuro-fuzzy inference system and ANN model were used in [13] to analyze the buckling of slender prismatic columns with a single nonpropagating open edge crack subjected to axial loads. Based on experimental data set, Baseri et al. [14] developed a fuzzy learning back-propagation algorithm capable to predict the springback in case of $\mathrm{V}$-die bending process. They compared the performance of the developed model in training and testing with the performance of the constant and the variable learning rate back-propagation algorithms. Liu in [15], developed a model based on ANN and a genetic algorithm capable to solve the springback problem which affects the quality of parts subjected to Ubending process. Nasrollahi and Arezoo in [16] used finite element methods (FEM) for springback simulation of the wipe bending of perforated components. The authors used the data sets obtained from simulation to train 2 artificial neural networks.

$\mathrm{Fu}$ in [17] carried out a series of experiments related to air-bending of metallic sheets. The obtained results were used to train and test an ANN model developed for punch radius prediction. In this study the weights of neural network were optimized by the author using a genetic algorithm after that, with the predicted radius for punch, as well as other geometrical parameters of the tool, 2D and 3D ABAQUS finite-element models were conducted. Kazan in [18] used finite element methods to simulate the springback which affects the wipe-bending processes. The data sets obtained from simulation were used to train an ANN model.

Springback is a very important factor that influences the quality of the bent parts, thus an accurate determination of this parameter is very important for manufacturers. Nowadays the time to market and low cost are essential for any manufacturers to fight competition.

Some authors [19] have made diagrams on which the springback coefficient can be determined, but they are not universal and cannot be applied in the case of any deformation circumstances or type of material.

Experimentally determination of springback involves high costs and time. Finding methods that predict the springback fast and accurately, without the need of 
experimental tests, is a goal for any company that produces parts obtained by bending operations. Finite element method is often used in springback prediction, but in some cases, especially in the case of complex parts it may be time consuming. Therefore, in this paper an artificial neural network model is proposed as an alternative to solve the prediction problem of springback which affects the free cylindrical bending process of metallic sheets. The proposed ANN model is validated by comparison with FEM results proving its high accuracy and predictive capabilities.

\section{OBTAINING DATA SET FOR SPRINGBACK COEFFICIENT PREDICTION}

To get the desired data for preparation, assessing and confirmation of the ANN model, free cylindrical bending experiments and Finite Element (FE) simulation of the free cylindrical bending process were performed.

\subsection{Experimental Procedure}

The experiments were conducted with the aid of a free cylindrical bending device (Fig. 1) which was installed on a universal mechanical testing machine INSTRON 1196. The active elements of the bending device have seven different radii: $10,15,20,25,30,35$ and $40 \mathrm{~mm}$.

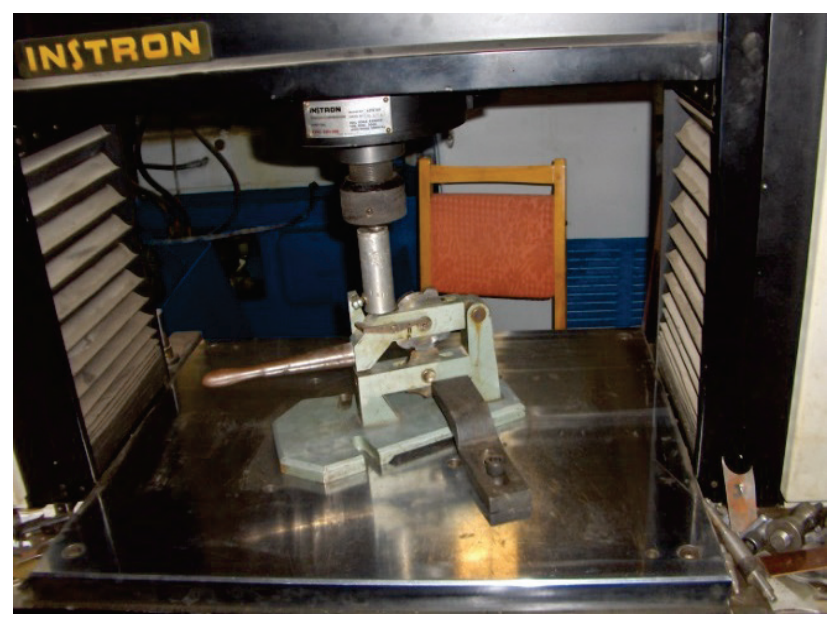

Figure 1 Bending stand setting

The experiments were done using a rectangular model (length $=25 \mathrm{~mm}$ and width $=10 \mathrm{~mm}$ ) obtained from aluminium alloy EN AW 6016 with the thickness of 1.25 $\mathrm{mm}$. The profile of the bent specimens was measured on a Werth Benchtop VideoCheck ${ }^{\circledR} \quad$ IP 400 coordinate measuring machine (Fig. 2). The obtained data have been used to establish the springback coefficient.

The device shown above was used in order to obtain six bending experiments for each determination. Then we have calculated the average of these six individual values. The springback coefficient $K$ was calculated according to equation Eq. (1) from reference [19] in order to highlight the accuracy of the parts after bending operation.

$$
K=\frac{R_{1}+\frac{t}{2}}{R+\frac{t}{2}}
$$

where: $R_{1}$ - die radius, $t$ - thickness of the specimen, $R$-part radius.

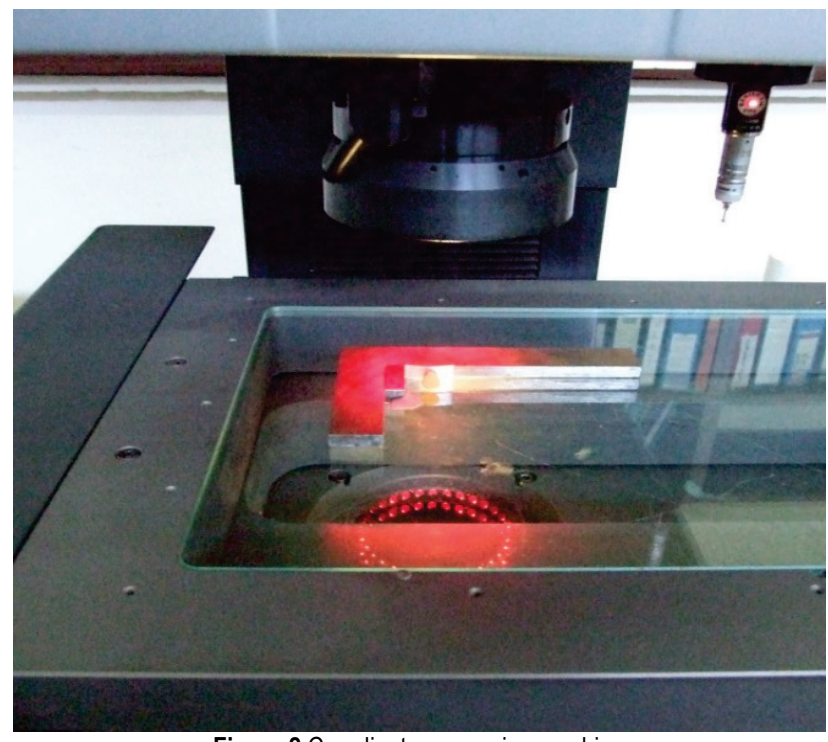

Figure 2 Coordinate measuring machine

\subsection{Finite Element Analysis}

Finite element simulation (FE) is justified by the necessity of enriching the experimental data to a volume that enables training, validation and testing of the ANN model.

In order to simulate the process of finite element analysis of the process of free cylindrical bending of the sheets, the ABAQUS/Standard Software was chosen.

Numerical tests focused on the investigation of the elastic recovery dependence on the mechanical properties, the nominal sheet thickness, bending radius and the friction between the specimen and active elements of the die. The following variable parameters were used in the simulations:

- $\quad$ sheet thickness $t=0.6,0.8,1,1.25,1.5,2 \mathrm{~mm}$;

- $\quad$ punch radius $r_{\mathrm{p}}=10,15,20,25,30,35,40 \mathrm{~mm}$;

- coefficient of friction $\mu=0.01,0.09,0.15$.

In the specialized literature, the repetition is specified of the free bending process, for each of the parameters given above.

In order to automatize the simulation tests, a monitoring program was developed. It repeatedly launched the ABAQUS/Standard software, providing each time another set of parameters of the bending process. Once a numerical test was finished, the monitoring program extracted from the corresponding output file the coordinates of two nodes located on the median fibre of the specimen. More precisely, the coordinate of node 1 located on symmetry axis of the specimen and of node 15 located at the middle of the bent region (Fig. 3) were used for this determination.

The coordinates of the nodes 1 and 15 from Fig. 3 were used to determine the radius obtained after the extraction of the bent part from the bending die:

$R=\frac{x_{15}^{2}+\left(y_{15}-y_{1}\right)^{2}}{2 \cdot\left(y_{15}-y_{1}\right)}$ 
Knowing the radius after removing the specimen from the bending die, the spring back coefficient $K$ can be calculated using Eq. (1). By the use of this methodology, the data sets obtained from technological free cylindrical bending experiments were significantly increased.

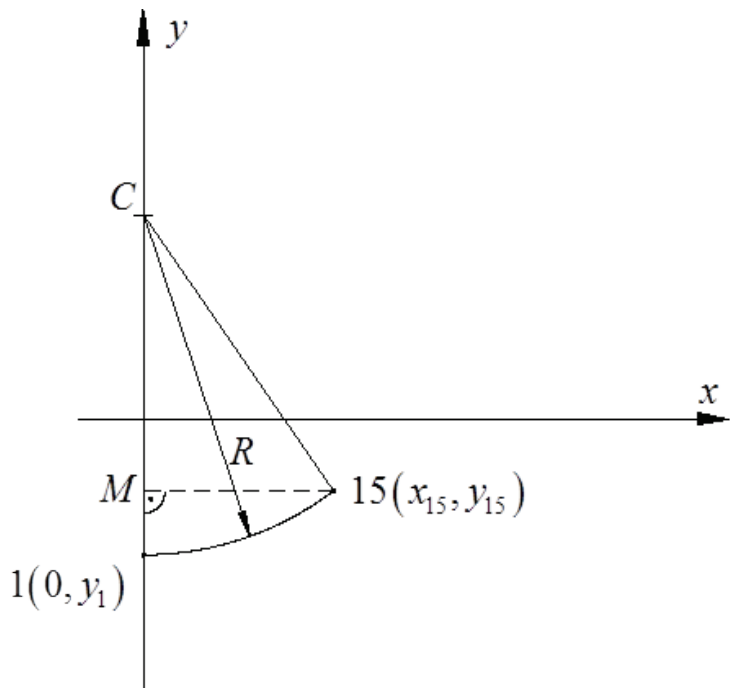

Figure 3 Geometric scheme used for the determination of the radius after removing the part from the bending die

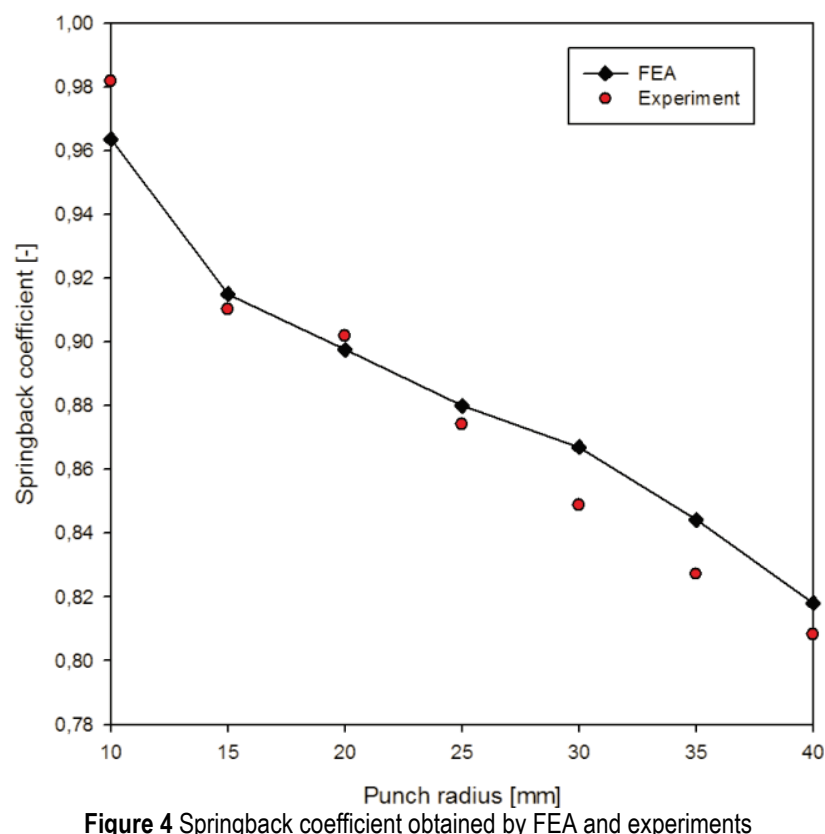

The active elements of tools (punch, die) are defined analytically. The mesh of this model had: 25 finite elements B21 (Beam elements with two nodes) and 26 equidistant nodes. Two nodes of reference were used to control the tools (punch and die) positions. The coefficient of friction is the same for both die and punch. The contact between the raw part and tools is the Coulomb type.

The expression of the Swift hardening law adopted in the simulation is as follows:

$\sigma_{\mathrm{c}}=C\left(\varepsilon_{0}+\varepsilon_{\mathrm{p}}\right)^{n}$

In order to be sure of the correctness and representativeness of the numerical results, the predictions of the program ABAQUS/Standard were compared with experimental data previously obtained (Fig. 4 and Tab. 1).

Where the relative error $(R E)$ was calculated as follows:

$$
R E=\left|\frac{\text { predicted }- \text { exp erimental }}{\text { experimental }}\right| \cdot 100, \%
$$

Table 1 Comparison of the springback prediction provided by FE Simulation and experiments

\begin{tabular}{|c|c|c|c|c|}
\hline & \multirow{2}{*}{$\begin{array}{c}\text { Punch } \\
\text { radius / mm }\end{array}$} & \multicolumn{2}{|c|}{ Springback coefficient } & \multirow{2}{*}{$\begin{array}{c}\text { Relative } \\
\text { error / \% }\end{array}$} \\
\cline { 3 - 4 } & 10 & Experimental & FEM prediction & 1.91 \\
\hline 1 & 15 & 0.9635 & 0.9819 & 0.50 \\
\hline 3 & 20 & 0.9149 & 0.9104 & 0.49 \\
\hline 4 & 25 & 0.8976 & 0.9019 & 0.65 \\
\hline 5 & 30 & 0.8670 & 0.8743 & 2.08 \\
\hline 6 & 35 & 0.8442 & 0.8489 & 2.01 \\
\hline 7 & 40 & 0.8181 & 0.8273 & 1.20 \\
\hline
\end{tabular}

The comparison showed relative errors less than $2.1 \%$ (Tab. 1), confirming the validity of the simulations.

Therefore the accuracy of the FEA results allows the use of data set obtained for training and testing the ANN model.

\section{NEURAL NETWORK MODEL FOR SPRINGBACK PREDICTION}

The characteristic of the ANN model is the ability of teaching and generalizing the things learned. This model offers a mapping function with data from input to output. This determines information about the practical phenomena. Neural networks are very complex phenomena, which nonlinear models cannot describe. For these reasons all models that have an adequate number of datasets can be simulated using ANN [18].

\subsection{Data Set for ANN}

In order to predict the springback coefficient, the neural network was developed using Matlab Software. Usually, the selection of the network inputs is a quite difficult problem compared with that of the network outputs that are clearly imposed by the specificity of the problem analysed, whereas the inputs are not. The springback phenomenon depends on many factors some of them being strongly correlated. Therefore, in this paper 3 input parameters and one output (target) parameter were chosen to develop the neural network model as follows: sheet thickness, punch radius, coefficient of friction for input and the springback coefficient as output (directly imposed by the application). The input and the output parameters of the ANN are called the data sets.

\subsection{ANN Architecture}

In this study was developed an ANN model with three layers: one input layer having 3 neurons, where input data (sheet thickness, punch radius and friction coefficient) is presented to the network, one hidden layer and an output layer with one neuron representing springback coefficient of the free cylindrical bent sheet. The structure of the proposed ANN model is presented in Fig. 5. 


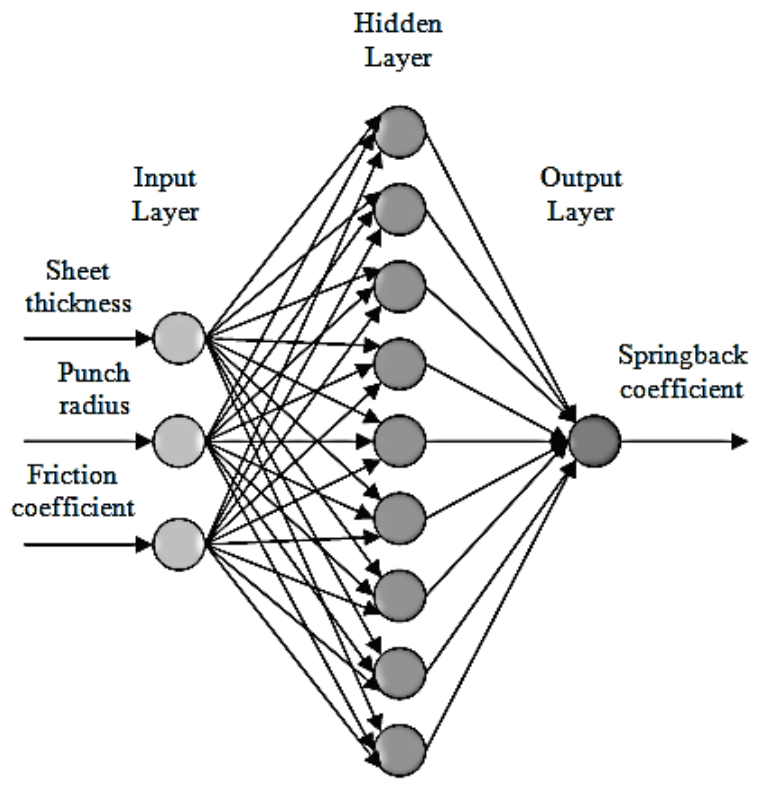

Figure 5 The proposed ANN model for springback prediction

The back-propagation neural network was trained by 107 data sets and tested by 19 data sets. In the training process the connection weights are assigned in order to reduce the error between the predicted and actual target value to a satisfactory level. Therefore, the connection weights were updated till the minimization of the defined error function is accomplished. The Levenberg-Marquardt back-propagation algorithm was chosen for training of the neural network. Once the training process is done the neural network should be a model able to predict the target value given the input pattern. For the test phase, a model with all parameters (including the connection weights) not used in the training phase was used. In order to evaluate the accuracy of the proposed ANN model, in predicting the springback coefficient of the free cylindrical bending process, the deviations of the ANN outputs from the finite element method (target data) were performed using standard statistical analyses such as the root mean squared error (RMSE) and the coefficient of determination $\left(R^{2}\right)$. These statistical measures used were calculated with the aid of Eqs. (5) and (6) as follows:

$$
\begin{aligned}
& R M S E=\sqrt{\frac{1}{N} \sum_{i=1}^{N}\left(a_{i}-p_{i}\right)^{2}} \\
& R=\frac{n \sum a p-\left(\sum a\right)\left(\sum p\right)}{\sqrt{n\left(\sum a^{2}\right)-\left(\sum a\right)^{2}} \sqrt{n\left(\sum p^{2}\right)-\left(\sum p\right)^{2}}}
\end{aligned}
$$

where: $N$ is the number of patterns; $a$ is the actual value from experiments; $p$ is the predicted value by models.

The optimal network architecture that results from trials and the parameters that maximize the $R^{2}$ values and minimize the RMSE is highlighted below:

- The number of input layer neurons is 3;

- The number of hidden layers is 1 ;

- The number of hidden layer neurons is 9;

- The number of output layer neurons is 1 ;

- $\quad$ The learning rate is 0.3 ;

- $\quad$ The momentum rate is 0.9 .

\subsection{Results}

During the training process of the neural network the weights have been updated until the error reached the value of $1.34 \times 10^{-4}$. Fig. 6 shows the change of the error performance during the training process. Preparation of this network was completed after 8 iterations when the expected value of performance of the network error was reached as seen in Fig. 6.
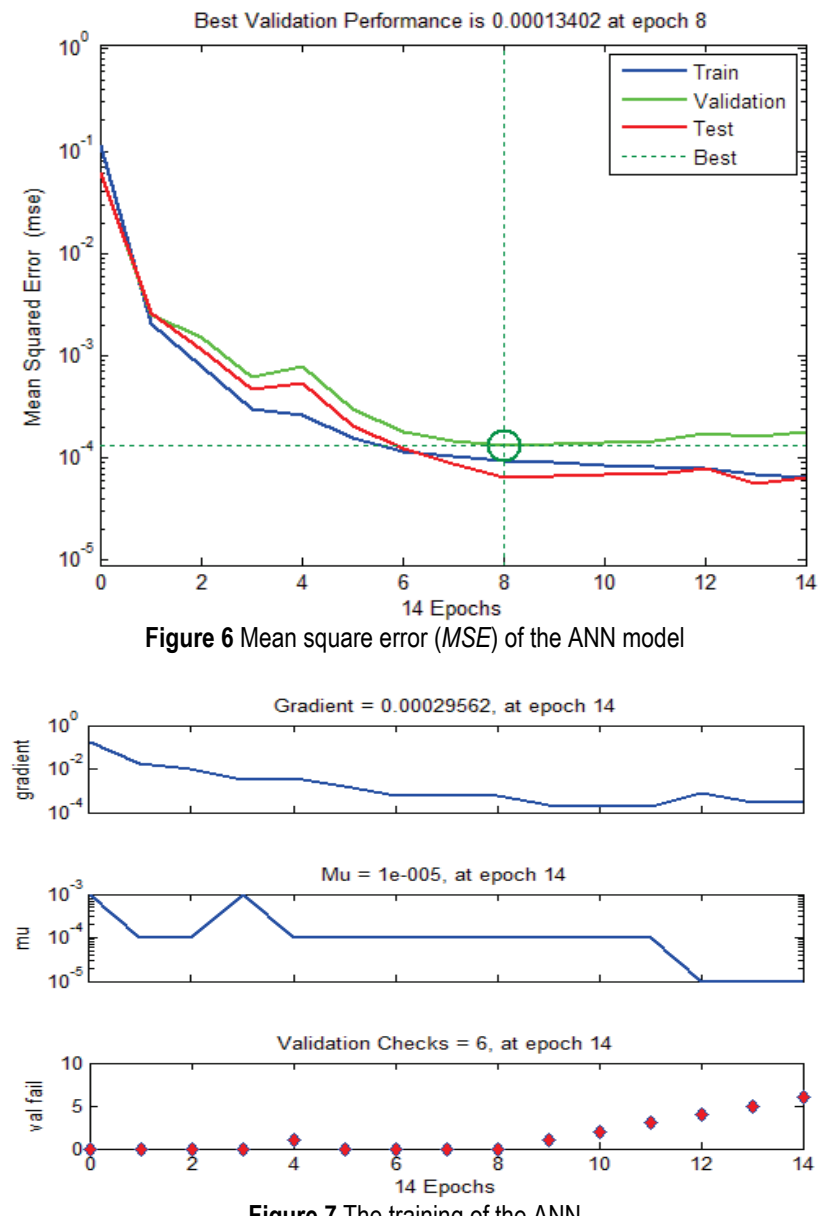

Figure 7 The training of the ANN

The training process of the artificial neural network is shown in Fig. 7.

Statistical measures such as the squared regression $\left(R^{2}\right)$ and root mean squared error ( $\left.R M S E\right)$ values were used to evaluate the developed model.

Fig. 8 shows the regression $(R)$ analyses of the data as criteria of model accuracy. The correlation between results and targets are regression values. In the following regression, plots can be observed the network outputs with respect to the targets for training, validation and testing sets. Therefore, Fig. 8a displays the regression analysis of the training data, Fig. $8 \mathrm{~b}$ presents the regression analysis of the validating data, Fig. 8c shows the regression analysis of the testing data and Fig. 8d depicts the total regression for the proposed ANN. The correlation coefficient of regression analysis is as follows: 0.99496 for the training data, 0.99246 for the validating data, 0.9967 for the testing data and finally 0.99459 for all the data.

All the correlation coefficients for the regression analysis shown in Fig. 8 have the value close to 1 ( $R$ value of 1 means a close relationship). In conclusion, the 
proposed neural network model could learn the relationship between the input parameters and the output parameter.

In this paper, the relative error $(R E)$ calculated using Eq. (4), was also used to evaluate the performance of the ANN model.
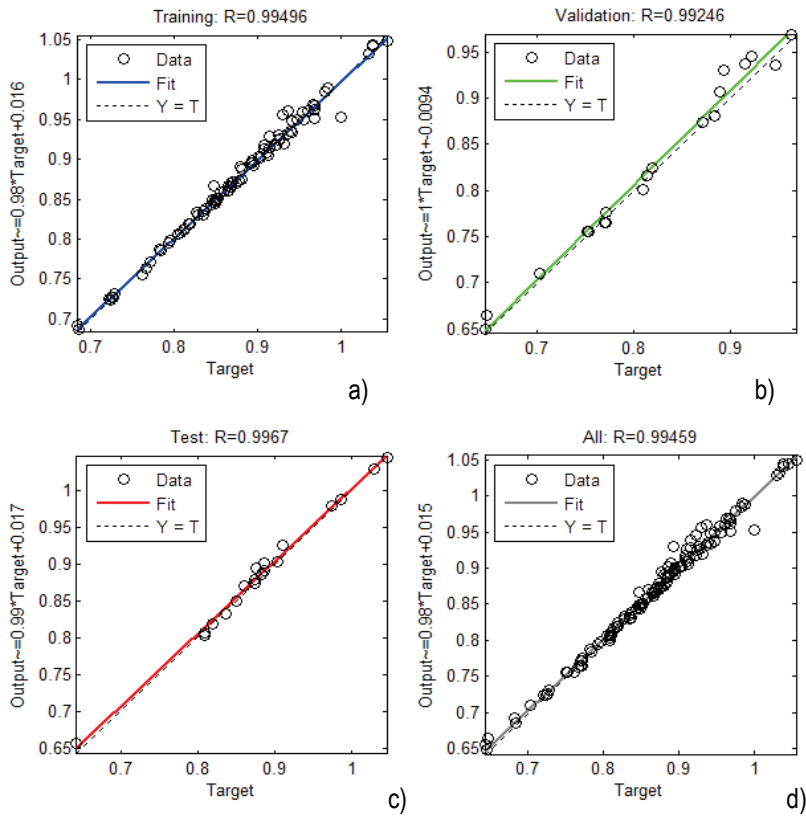

Figure 8 The data regression of the proposed ANN model

The results obtained for relative errors $(R E)$ are shown in Tab. 2. One may notice that the constructed ANN model provides good prediction performances being able to fit most of the springback coefficient values close to the target springback coefficient. All the 19 testing data sets have relative errors less than 0.0212 . This means that the results obtained by the ANN model are in concordance with the obtained results by FEM showing the accuracy of the model.

Table 2 Confrontation of the actual values with the ANN results

\begin{tabular}{|c|c|c|c|}
\hline No. & FEM & ANN & Relativ error $R E$ \\
\hline 1 & 0.9753 & 0.9795 & 0.0043 \\
\hline 2 & 1.0293 & 1.0283 & 0.0010 \\
\hline 3 & 0.9873 & 0.9874 & 0.0000 \\
\hline 4 & 0.9031 & 0.9030 & 0.0001 \\
\hline 5 & 0.8861 & 0.9017 & 0.0176 \\
\hline 6 & 0.8093 & 0.8027 & 0.0082 \\
\hline 7 & 0.8601 & 0.8710 & 0.0126 \\
\hline 8 & 0.8769 & 0.8939 & 0.0194 \\
\hline 9 & 0.6429 & 0.6565 & 0.0212 \\
\hline 10 & 0.8503 & 0.8498 & 0.0006 \\
\hline 11 & 0.8749 & 0.8730 & 0.0021 \\
\hline 12 & 0.8870 & 0.8907 & 0.0042 \\
\hline 13 & 0.8190 & 0.8188 & 0.0003 \\
\hline 14 & 0.8097 & 0.8065 & 0.0039 \\
\hline 15 & 0.8360 & 0.8324 & 0.0043 \\
\hline 16 & 1.0460 & 1.0445 & 0.0014 \\
\hline 17 & 0.8840 & 0.8861 & 0.0025 \\
\hline 18 & 0.9104 & 0.9262 & 0.0174 \\
\hline 19 & 0.8743 & 0.8795 & 0.0060 \\
\hline
\end{tabular}

Fig. 9 presents a graphic comparison between the ANN output results and the target results obtained by FEM. It is important to mention that most of the results obtained with ANN are relatively close to those obtained by FEA demonstrating that the constructed ANN model and FEA are close to the prediction of the springback coefficient values.

The performance of this ANN model can be increased by adding more parameters, such as material's properties.

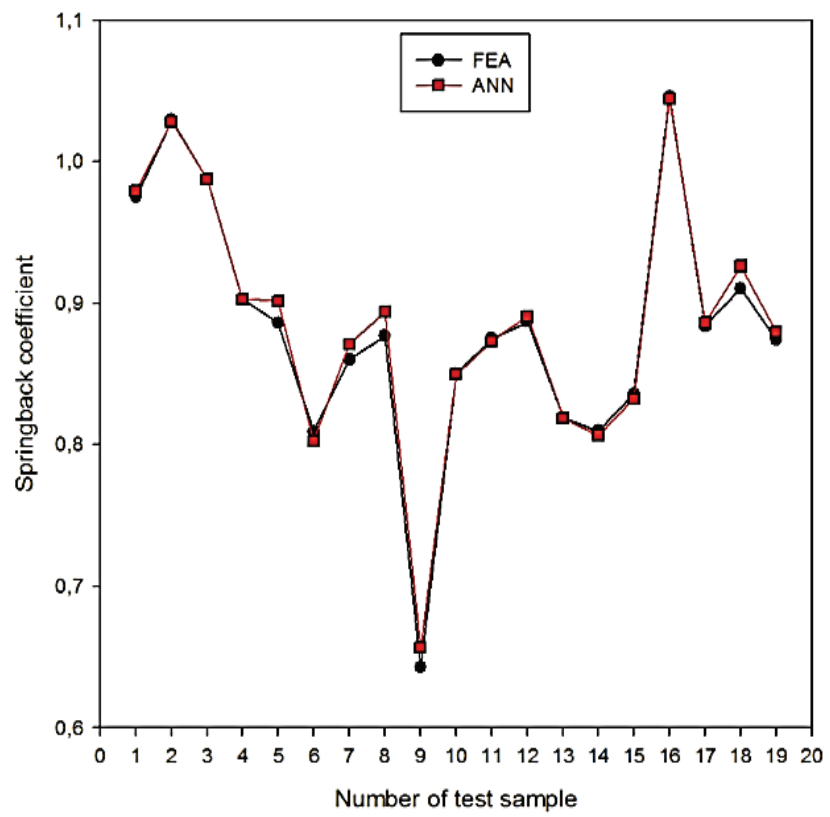

Figure 9 The confrontation of data from ANN with FEA for springback coefficient

\section{CONCLUSIONS}

The goal of this paper was to develop a backpropagation neural network model able to predict the springback coefficient in the free cylindrical bending process of metallic sheets. For this purpose a database of 126 tests obtained from FEM was used for training and testing this model and 3 variables were selected as inputs for the ANN model.

The ANN model proposed for characterizing the springback phenomenon in the free cylindrical bending process of metallic sheets was successfully developed and used to predict the springback coefficient. The statistical measures (squared regression and root mean squared error values) used to evaluate the developed model confirm that the developed model is at a high level of accuracy.

A good agreement has been noticed between the values predicted by ANN and the target values obtained by FEM. ANNs require adequate number of data sets in order to act and learn efficiently. To achieve this goal the experimental data were enriched, using finite element simulation, to a volume that enables training, validation and testing of the ANN model. On the other hand Finite Element method in some cases, especially in the case of complex parts may be time consuming. Using the ANN model the computation time was significantly reduced.

Therefore the use of ANN technique in combination with FEM reduces time and cost of required experiments, the fact that is very important for bent parts manufacturers for which the time to market and low cost are essential to fight competition.

The approach proposed by the authors is able to provide accurate predictions, as proved by the comparison with experimental and FE results. In the future research, 
the authors plan to improve the ANN capabilities by adding more input parameters.

\section{REFERENCES}

[1] Fazilat, H., Ghatarband, M., Mazinani, S., Asadi, Z. A., Shiri, M. E., \& Kalaee, M. R. (2012). Predicting the mechanical properties of glass fiber reinforced polymers via artificial neural network and adaptive neuro-fuzzy inference system. Computational Materials Science, 58, 31-37. https://doi.org/10.1016/j.commatsci.2012.01.012

[2] Dote, Y. \& Ovaska, S. J. (2001). Industrial applications of soft computing: a review. Proceedings of the IEEE, 89(9), 1243-1265. https://doi.org/10.1109/5.949483

[3] Kaynak, O., Zadeh, L. A., Türkşen, B., \& Rudas, I. J (Eds.). (1998). Fuzzy Inference Systems: A Critical Review. Computational Intelligence: Soft Computing and FuzzyNeuro Integration with Applications, 162, Berlin, Springer Book. https://doi.org/10.1007/978-3-642-58930-0

[4] Hanna, M. A., Ural, D., \& Saygili, G. (2007). Evaluation of liquefaction potential of soil deposits using artificial neural networks. Engineering Computations, 24, 5-16. https://doi.org/10.1108/02644400710718547

[5] Padmini, D., Ilamparuthi, K., \& Sudheer, K. P. (2008). Ultimate bearing capacity prediction of shallow foundations on cohesionless soils using neurofuzzy models. Computer Geotechnics, 35(1), 33-46. https://doi.org/10.1016/j.compgeo.2007.03.001

[6] Alanis, A., Arana-Daniel, N., \& Lopez-Franco, C. (2019). Artificial neural networks for Engineering Applications, $1^{\text {st }}$ Edition, eBook ISBN:9780128182482, Elsevier Book.

[7] Mashrei, M. A., Abdulrazzaq, N., Abdalla, T. Y., \& Rahman, M. S. (2010). Neural networks model and adaptive neurofuzzy inference system for predicting the moment capacity of ferrocement members. Engineering Structures, 32(6), 1723-1734. https://doi.org/10.1016/j.engstruct.2010.02.024

[8] Abiodun, O. I., Jantan, A., Omolara, A. E., Dada, K. V., Mohamed, N. A., \& Arshad, H. (2018). State-of-the-art in artificial neural network applications: A survey. Heliyon, 4(11). https://doi.org/10.1016/j.heliyon.2018.e00938

[9] Xu, J., Zhao, J., Song, Z., \& Liu, M. (2012). Prediction of ultimate bearing capacity of Tubular T-joint under fire using artificial neural networks. Safety Science, 50(7), 1495-1501. https://doi.org/10.1016/j.ssci.2012.02.004

[10] Ghaisari, J., Jannesari, H., \& Vatani, M. (2012). Artificial neural network predictors for mechanical properties of cold rolling products. Advances in Engineering Software, 45(1), 91-99. https://doi.org/10.1016/j.advengsoft.2011.09.016

[11] Zgoul, M. H. (2012). Use of artificial neural networks for modelling rate dependent behaviour of adhesive materials. International Journal of Adhesion \& Adhesives, 36, 1-7. https://doi.org/10.1016/j.ijadhadh.2012.03.003

[12] Duan, Z. H., Kou, S. C., \& Poon, C. S. (2013). Prediction of compressive strength of recycled aggregate concrete using artificial neural networks. Construction and Building Materials, 40, 1200-1206. https://doi.org/10.1016/j.conbuildmat.2012.04.063

[13] Bilgehan, M. (2011). Comparison of ANFIS and NN models-with a study in critical buckling load estimation. Applied Soft Computing, 11(4), 3779-3791. https://doi.org/10.1016/j.asoc.2011.02.011

[14] Baseri, H., Bakhshi-Jooybar, I. M., \& Rahmani, B. (2011). Modeling of Spring-back in V-die Bending Process by Using Fuzzy Learning Back-propagation Algorithm. Expert Systems with Applications, 38, 8894-8900. https://doi.org/10.1016/j.eswa.2011.01.102

[15] Liu, W., Liu, Q., Ruan, F., Liang, Z., \& Qiu, H. (2007) Springback prediction for sheet metal forming based on GA-
ANN technology. Journal of Materials Processing Technology, 187-188, 227-231. https://doi.org/10.1016/j.jmatprotec.2006.11.087

[16] Nasrollahi, V. \& Arezoo B. (2012). Prediction of springback in sheet metal components with holes on the bending area, using experiments, finite element and neural networks. Materials and Design, 36, 331-336. https://doi.org/10.1016/j.matdes.2011.11.039

[17] Fu, Z., Mo, J., Chen, L., \& Chen, W. (2010). Using genetic algorithm-back propagation neural network prediction and finite-element model simulation to optimize the process of multiple-step incremental air-bending forming of sheet metal. Materials and Design, 31(1), 267-277. https://doi.org/10.1016/j.matdes.2009.06.019

[18] Kazan, R., Firat, M., \& Tiryaki, A. E. (2009). Prediction of spring back in wipe-bending process of sheet metal using neural network. Materials and Design, 30(2), 418-423. https://doi.org/10.1016/j.matdes.2008.05.033

[19] Smith, D. A. (1990). Die Design Handbook, $3^{\text {rd }}$ ed., Society of Manufacturing Engineers, Dearborn, MI.

\section{Contact information:}

Florica Mioara SERBAN, Assistant PhD

Faculty of Electrical Engineering,

Technical University of Cluj-Napoca,

Str. G. Bariţiu nr. 26-28,

400027 Cluj-Napoca, Romania

E-mail: florica.serban@edr.utcluj.ro

Sorin Dumitru GROZAV, Professor PhD

(Corresponding author)

Faculty of Machine Building,

Technical University of Cluj-Napoca,

B-dul Muncii 103-105,

400641 Cluj-Napoca, Romania

E-mail: Sorin.Grozav@tcm.utcluj.ro

Vasile Adrian CECLAN, Assistant PhD

Faculty of Machine Building

Technical University of Cluj-Napoca,

B-dul Muncii 103-105,

400641 Cluj-Napoca, Romania

E-mail: Vasile.Ceclan@tcm.utcluj.ro

Antoniu TURCU, Lecturer PhD

Faculty of Electrical Engineering,

Technical University of Cluj-Napoca,

Str. G. Bariţiu nr. 26-28,

400027 Cluj-Napoca, Romania

E-mail: antoniu.turcu@enm.utcluj.ro 